\title{
AIDS-Related Kaposi Sarcoma S (Systemic Illness) Status
}

National Cancer Institute

\section{Source}

National Cancer Institute. AIDS-Related Kaposi Sarcoma S (Systemic IIIness) Status. NCI

Thesaurus. Code C134981.

A term that refers to the systemic illness status of AIDS-related Kaposi sarcoma

according to the AIDS Clinical T rials Group system. (American Cancer Society) 